Article

\title{
Impacts of Farming Layer Constructions on Cultivated Land Quality under the Cultivated Land Balance Policy
}

\author{
Long Kang ${ }^{1,+}$, Rui Zhao ${ }^{1,+}$, Kening Wu ${ }^{1,2,3, * \mathbb{D}}$, Qin Huang ${ }^{1}$ and Sicheng Zhang ${ }^{1}$ \\ 1 School of Land Science and Technology, China University of Geosciences, Beijing 100083, China; \\ 2112200053@cugb.edu.cn (L.K.); zhaoruifighting@cugb.edu.cn (R.Z.); hq@cugb.edu.cn (Q.H.); \\ 2112200054@cugb.edu.cn (S.Z.) \\ 2 Key Laboratory of Land Consolidation and Rehabilitation, Ministry of Natural Resources, \\ Beijing 100035, China \\ 3 Technology Innovation Center of Land Engineering, Ministry of Natural Resources, Beijing 100083, China \\ * Correspondence: wukening@cugb.edu.cn \\ + These authors contributed equally to this work.
}

check for updates

Citation: Kang, L.; Zhao, R.; Wu, K.; Huang, Q.; Zhang, S. Impacts of Farming Layer Constructions on Cultivated Land Quality under the Cultivated Land Balance Policy. Agronomy 2021, 11, 2403. https://doi.org/10.3390/ agronomy11122403

Academic Editors: Long Guo, Xiaodong Song, Abdul M. Mouazen and Peng Fu

Received: 4 October 2021

Accepted: 23 November 2021

Published: 25 November 2021

Publisher's Note: MDPI stays neutral with regard to jurisdictional claims in published maps and institutional affiliations.

Copyright: (c) 2021 by the authors. Licensee MDPI, Basel, Switzerland. This article is an open access article distributed under the terms and conditions of the Creative Commons Attribution (CC BY) license (https:// creativecommons.org/licenses/by/ $4.0 /)$.
Abstract: Cultivated Land Balance Policy (CLBP) has led to the "better land occupied and worse land supplemented" program. At the same time, the current field-scale cultivated land quality (CLQ) evaluation cannot meet the work requirements of the CLBP. To this end, this study selected 24 newly added farmland in Fuping County and performed eight different high quality farming layer construction experiments to improve the CLQ. A new comprehensive model was constructed on a field scale to evaluate the CLQ using different tests from multi-dimensional perspectives of soil fertility, engineering, environment, and ecology, and to determine the best test mode. The results showed that after the test, around $62 \%$ of the cultivated land improved by one level, and the average cultivated land quality level and quality index of the test area increased by 0.63 and 30.63, respectively. The treatment of "woody peat + rotten crop straw + biostimulation regulator II + conventional fertilization" had the best effect on the improvement of organic matter, soil aggregates, and soil microbial activity, and was the best treatment method. In general, application of soil amendments, such as woody peat when constructing high quality farmland, could quickly improve CLQ, and field-scale CLQ evaluation model constructed from a multi-dimensional perspective could accurately assess the true quality of farmland and allow managers to improve and manage arable land resources under CLBP.

Keywords: cultivated land quality evaluation; field scale; high-quality farming layer; woody peat

\section{Introduction}

Cultivated Land Balance Policy (CLBP) is a basic cultivated land protection policy established by China to maintain the dynamic balance of the total cultivated land [1], and is one of the core systems established by the "Land Management Law" [2]. This policy is a remedial measure for large-scale occupation of cultivated land by industrialization and urbanization, and plays an important role in ensuring the country's food security [3,4]. The basic principle of CLBP is that the cultivated land approved for non-agricultural construction should be supplemented by land improvement and development with the amount and quality of cultivated land equivalent to that of the occupied cultivated land, i.e., "excellent and supplementary" [5]. However, the cultivated land supplemented by land improvement has serious quality problems that are prominently manifested in the lack of high-quality farming layers [6], leading to the balance policy of arable land occupancy compensation, which equalizes the existence of "predominantly superior and compensating inferiority". The fertile farming layer, also called the high quality farming layer, is formed through long-term cultivation, and is characterized by obvious soil aggregate structure, high organic matter content and microbial activity, and strong feeding ability [7]. Timeliness 
indicates that newly reclaimed cultivated land cannot be replaced after many years of cultivation. In a previous study, Bing et al. revealed the main influencing factors that require long cultivation time by studying the characteristics of long-term cultivated high quality farming layers, and proposed the principle of rapid construction of high quality farming layers [6,8], i.e., soil organic matter-soil aggregates-synergistic mechanism of biological activity.

Construction of a high quality farming layer is essentially a soil improvement approach, and many studies on soil improvement have been conducted around the world. Although organic cultivation is an effective measure recommended globally [9], the process of organic fertilization is relatively lengthy, and long-term excessive use of organic manure from livestock and poultry can increase the heavy metals content in the soil and enhance the risk of heavy metals absorption and accumulation by crops [10]. In addition, with the development of the concept of "soil health", many countries have promoted cover crops at a sweeping speed to increase the efficiency of soil nutrients cycling and improve soil physical and chemical properties [11,12]. This method mainly contributes to the easily decomposable part of the soil organic matter, which is difficult to accumulate $[13,14]$. In addition, the bio-improvement technology, which can enhance soil organic matter and fertility by identifying and domesticating soil microbial populations, is very cost-effective and efficient $[15,16]$. In recent years, woody peat has received widespread attention as a new type of improver. Woody peat is an intermediate product of the conversion of plant residues to coal. It is rich in humus [17-19], and is the main component of soil organic matter and a kind of biochar with high humic acid content [20]. In the present study, based on the principle of high-quality farming layer construction proposed in earlier reports, we selected four platforms in the experimental area of Fuping County, Hebei Province, China, as the research area. Rapid construction of high quality farming layer with natural organic materials as the core was accomplished by applying woody peat to increase the hard-todecompose organic matter (humus) of the soil, adding decomposed straw to increase the easily decomposable (active) organic matter of the soil (similar to the principle of cover crops), and introducing biological stimulants to increase the diversity and abundance of soil microorganisms to activate woody peat (similar to the principle of biological improvement). In addition, we also designed experiments with different materials at diverse ratios in combination with traditional fertilizers, and further compared and studied the effects of high-quality farming layer construction with woody peat as the core.

According to CLBP, the occupied and supplemented arable land indicators are transferred based on cultivated land quality (CLQ) $[4,5]$. Therefore, we considered accurate evaluation of the improvement of CLQ after the construction of high-quality farming layers and determination of the best experimental mode as the key issues. The CLQ evaluation involved investigating national conditions and food security, which meant that it was an important study about natural resource management, and a crucial foundation for strengthening the red line protection of CLQ and the implementation of the CLBP [21]. The most common method used is to construct a comprehensive index system to quantitatively measure CLQ. The United States Department of Agriculture (USDA) developed the world's first quantitative evaluation system for arable land quality in 1961, which was based on the Land Capability Classification (LCC) system [22]. Furthermore, the Food and Agriculture Organization of the United Nations (FAO) developed the first unified evaluation system, the Land Evaluation Framework, in 1976, which was based on the principles of arable land suitability [23]. They used it as a model to optimize and develop the Land Evaluation and Site Assessment (LESA) [24], land quality indicators (LQIs) [25], and the Sustainable Land Use Management Project [26]. In the 1980s, Canada proposed using a combined soil health quality and soil environmental quality assessment to evaluate cultivated land quality [27]. In China, different management departments evaluate CLQ according to different management objectives and different evaluation factors: The Ministry of Natural Resources comprehensively considers land use conditions [28], the Ministry of Agriculture and Rural Affairs emphasizes soil fertility and food security [29], 
and the Ministry of Ecology and Environment focuses on soil pollution [30]. However, to date, the existing CLQ evaluation system still ignores the general principle that different evaluation purposes employ diverse evaluation scales [31]. The "Soil and Water Quality at Different Scales" seminar held in Wageningen, the Netherlands, 1996, systematically discussed the scale issues of soil quality assessment for the first time. It reported that different spatial scales and objects laid particular stress on different criteria, and that the methods and effects of evaluation are significantly different depending on the scale that had been chosen [32-34]. The CLQ evaluation at the field scale has higher accuracy and greater diversity of indicators, and thus, can better detect the changes in CLQ factors [35], which is conducive to the fine and differentiated management of cultivated land and meets the work needs of CLBP. The recent indicator systems of CLQ evaluation at the field scale are generally based on the physical, chemical, and biological aspects of the land and are used to explore the input-output efficiency of the field [36], the soil nutrient dynamics [37], and cultivated land effects on crops [38]. However, this assessment system, which focuses on determining soil fertility, obviously lacks in-depth research on the constituent elements, operation processes, and functions of the cultivated land system, and cannot fully consider the natural, economic, and ecological conditions of the cultivated land [39]. Therefore, there is an urgent need to develop a field-scale farmland quality evaluation system from a multi-dimensional perspective.

Accordingly, the present study conducted high quality farming layer construction experiments with woody peat and other organic materials as the core, developed fieldscale CLQ evaluation methods, evaluated the effects of CLQ verification experiments, and determined the best fertilization mode. In particular, this study mainly attempted to accomplish the following two goals: (1) construct a field-scale CLQ evaluation model from a multi-dimensional perspective and (2) determine the best quality farmland by evaluating and verifying the CLQ after the construction of high-quality farming layer and identifying the best fertilizer ratio, and applying the obtained data to CLBP. The results of this study linked CLBP with technical projects related to land reclamation and development to effectively improve the quality of arable land in barren mountainous areas. Besides, the findings will also help implement the national poverty alleviation policy, increase production and income, and have an important practical significance in achieving China's food security and sustainable economic and social development.

\section{Materials and Data Sources}

\subsection{Overview of the Test Area}

In 2015, Fuping County, Hebei Province, China, was established as a pilot county for the development and utilization of unused land resources suitable for farming. The county develops and organizes damaged construction land and unused land with a slope of less than 25 degrees into cultivated land, and helps farmers to overcome poverty through improvement and development of barren hills and unused land. The study area (Figure 1) was located in Xiaoshifang Village, Fuping Town, in the middle and south of Fuping County. The coordinates are $114^{\circ} 15^{\prime} 11^{\prime \prime}-114^{\circ} 16^{\prime} 41^{\prime \prime}$ east longitude, $38^{\circ} 48^{\prime} 26^{\prime \prime}-38^{\circ} 47^{\prime}$ north latitude $3^{\prime \prime}$. It is a low mountain and hilly area with an altitude of 300-350 m; the average annual temperature is $12.6^{\circ} \mathrm{C}$ and the accumulated temperature is $801.9^{\circ} \mathrm{C}$. The average annual rainfall is $550 \mathrm{~mm}, 80 \%$ of which occurs between June and August. The mountain is windy every afternoon and the frost-free period is 140-190 days. The soil is ochrepts, according to Soil Taxonomy. Weathering, gneiss movement, and nutrients and organic matter contents were regarded as the dominant limiting factors affecting agricultural production in the area. 


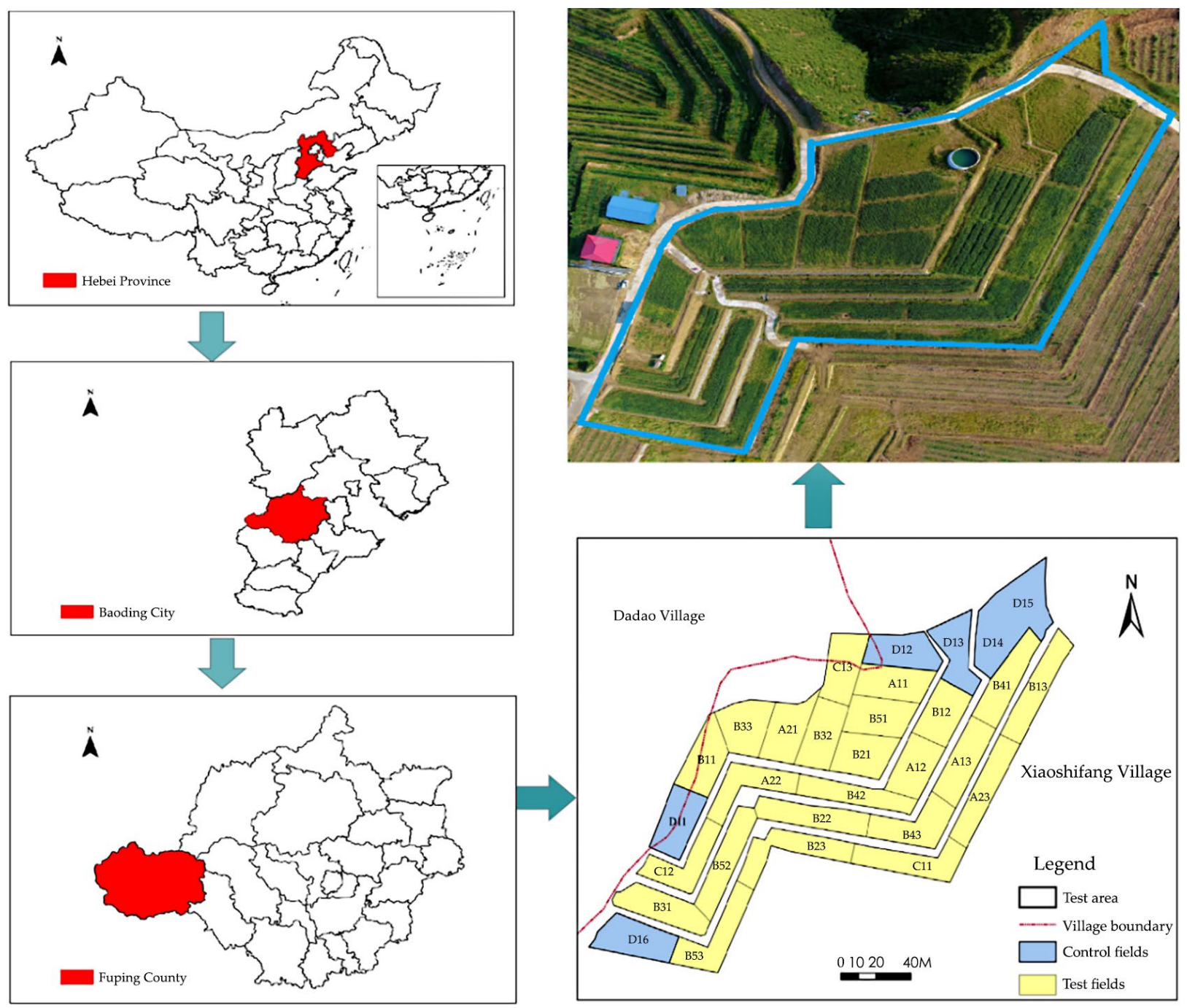

Figure 1. Location of the study area. Source: Drawn by the authors.

\subsection{Test Material and Design}

The main test material was woody peat. The auxiliary test materials were decomposed crop straw, biological stimulation regulators I \& II, composite fertilizer $\left(\mathrm{N}-\mathrm{P}_{2} \mathrm{O}_{5}-\mathrm{K}_{2} \mathrm{O}\right.$ : $25 \%-13 \%-8 \%$, total nutrient $\geq 46 \%$; Humic acid content ( $\geq 3 \%$ ), and urea ( $\mathrm{N} 46 \%)$. The test crop in this experiment was millet (Jigu No. 38), which is a high-quality, high-yielding, herbicide-resistant, lodging-resistant, disease-resistant variety that has been bred by the Millet Research Institute of Hebei Academy of Agriculture and Forestry Sciences. A total of eight treatments were set up with each treatment was repeated three times. The treatments were randomly distributed across 24 field units in the test area. The treatments were as follows:

A1: woody peat + decomposed crop straw + biological stimulation regulator $\mathrm{I}+$ conventional fertilizer (composite fertilizer + urea);

A2: woody peat + decomposed crop straw + biological stimulation regulator II + conventional fertilizer (composite fertilizer + urea);

B1: woody peat + decomposed crop straw + conventional fertilizer (composite fertilizer + urea);

B2: woody peat (reduction) + decomposed crop straw + conventional fertilization (composite fertilizer + urea);

B3: biochar + decomposed crop straw + conventional fertilizer (composite fertilizer + urea); 
B4: organic fertilizer (livestock manure)+ decomposed crop straw + conventional fertilizer (composite fertilizer + urea);

B5: decomposed crop straw + conventional fertilizer (composite fertilizer + urea);

C1: conventional fertilizer (composite fertilizer + urea).

The experiment started on 5 June 2017. Different combinations of materials were applied to the different treatments and then rotary mixing was carried out. The rotary tillage depth was $>20 \mathrm{~cm}$. On 15 June, sowing, weeding, and water and fertilizer management were undertaken according to accepted millet cultivation techniques. In October, millet harvesting, yield measurement, and soil sampling were completed. The divisions and codings for the CLQ units are shown in Figure 1. The numbers 1, 2, and 3 were added after the group codes. For instance, field unit A22 indicates that this field is the second field unit and was subjected to the A2 treatment. The remaining six fields in the area did not contain any experimental treatments and acted as controls for the experiment.

\subsection{Data Collection and Processing}

The research data mainly included geospatial data, soil data, project data and arable land spatial data. The slope data were collected from the spatial distribution data of the China Digital Elevation Model (http:/ /www.resdc.cn, accessed on 20 March 2019). The effective soil layer thickness and soil structure data were obtained from the second soil survey data of Hebei Province (1:50,000). We used the "five-point sampling method" or "snake sampling method" to collect soil samples from the $0-20 \mathrm{~cm}$ soil layer of each plot, and obtained other soil data through experimental analysis. In addition, the degree of irrigation assurance, drainage conditions, and water and soil conservation functions were determined with reference to the information on the irrigation, drainage, and water conservancy facility construction drawings and water and soil conservation facilities acceptance appraisal documents in the experimental area, along with field investigations. The spatial data of cultivated land were obtained from the survey data of land use change in Fuping County in 2017. The accessibility of field roads was determined by calculating the distance from the cultivated fields to field roads by using the distance analysis function in ArcGIS. The field uniformity was based on the plots of cultivated fields, and was characterized by the SHAPE value of the patch shape index in the landscape index.

\section{Methodology}

\subsection{Theoretical Framework for the Evaluation System}

Transforming natural environmental conditions affects socioeconomic development on cultivated land and changes population demands, but the CLQ concepts and connotations are still being developed. Initially, the United States Department of Agriculture proposed the Land Potential Classification System in 1961 [40]. The quality of cultivated land is mainly defined as the production potential of the cultivated land. The highest yields should be achieved when environmental and practical conditions, such as light, heat, water, and other climate resources, are optimized. In the 1980s, when the international community began to pay attention to soil and environmental health issues, Canada launched the "Soil Health" project [41], which included soil and environmental health when defining CLQ. In the 1990s, CLQ was principally defined in terms of productivity. By the early 21st century, the CLQ concept gradually embodied the ecological environment, ecological security, environmental quality, and sustainability. The CLQ definitions began to include suitability, production potential, actual productivity [42], ecology, and land bearing capacity [43]. Currently, CLQ is deemed to be a comprehensive concept with multiple levels. There are a number of quality dimensions that reflect the inherent elements of cultivated lands and their combined characteristics [44]. Previous studies suggested that the quality score for cultivated land should indicate its ability to maintain crop production, support modern agricultural production, meet safety requirements and the demands for healthy food, and maintain the sustainable use of cultivated land systems. 
The cultivated land system is a natural geo-socio-economic complex composed of climate, soil, parent material, topography, hydrology, vegetation, and human activities [45]. The quality of the cultivated land is based on the many functions performed by cultivated land elements, and the operation of cultivated land systems requires various physical, chemical, and biological processes [46]. For example, the water cycle and thermal movement can promote the absorption and utilization of water and nutrients by crops; biological processes, including humification, nutrient cycling, and photosynthesis, increase the nutrient levels required for crop growth and fix carbon dioxide to release oxygen; and chemical processes, which include ion exchange, acid-base reactions, and redox reactions, affect soil stability and fertility. These processes all affect nutrient availability and contribute to the movement of substances in the soil [47]. The cultivated land system also carries out many functions that are closely related to human life, such as material production, water conservation, soil conservation, and carbon retention [48,49]. Objectively, the functions of cultivated land are subjugated to the needs of human beings at different levels, which suggests that in the initial stage of socio-economic development, the primary requirement of cultivated land is to guarantee high-yields and efficient food production [50].

As time progresses, frequent food safety issues lead to calls for improved food health and safety [51,52], and eventually, sustainable land use is requested by the population as laid out in the United Nations Sustainable Development Goals. When socioeconomic development reaches a certain level, cultivated land needs to offer multiple functions and meet other human demands, such as leisure activities. These are often met using modern engineering and technical tools, but the different functions can often interact with each other. Overall, the human requirements of the cultivated land system are primarily based on production, ecology, and health. These diverse human demands have affected the elements and functions of cultivated land. The quality of cultivated land has been transformed from a single natural attribute to one with multiple features, such as nature, economy, and society. These attributes are based on factors such as soil fertility, topography and landforms, farming conditions, health, and pollution. The biological characteristics of cultivated land have a coordinated effect on the quality of cultivated land. In the soil quality grading scheme from Muencheberg in Germany [53], soil quality was evaluated using two dimensions: a base item and a risk item. The Canadian Agricultural Environmental Assessment System used four major factors: soil quality, farmland management, water quality, and air quality, to evaluate agricultural production [54]. This study selected an indicator system based on geological characteristics, soil features, farming conditions, health conditions, and biological conditions, which were based on four dimensions: soil fertility, engineering, environment, and the ecology of the cultivated land. These were used to establish the theoretical framework of the farmland quality evaluation system at the field scale (Figure 2).

\subsection{Construction of the Evaluation Index System}

With reference to the soil health evaluation system of Cornell University, USA, the field-scale soil quality evaluation index system of the United States Department of Agriculture, and the relevant regulations of China's CLQ evaluation, we selected a set of CLQ evaluation index systems applicable to the field scale (Table 1). In particular, our study was based on the theoretical framework of CLQ evaluation and an indicator system was constructed according to the principles of productivity, dominance, feasibility, and comprehensiveness. The study included four dimensions of soil fertility quality, engineering quality, environmental quality, and ecological quality; five first level indicators of topography, soil properties, farming conditions, pollution status, and biological characteristics; and several second-level indicators. 


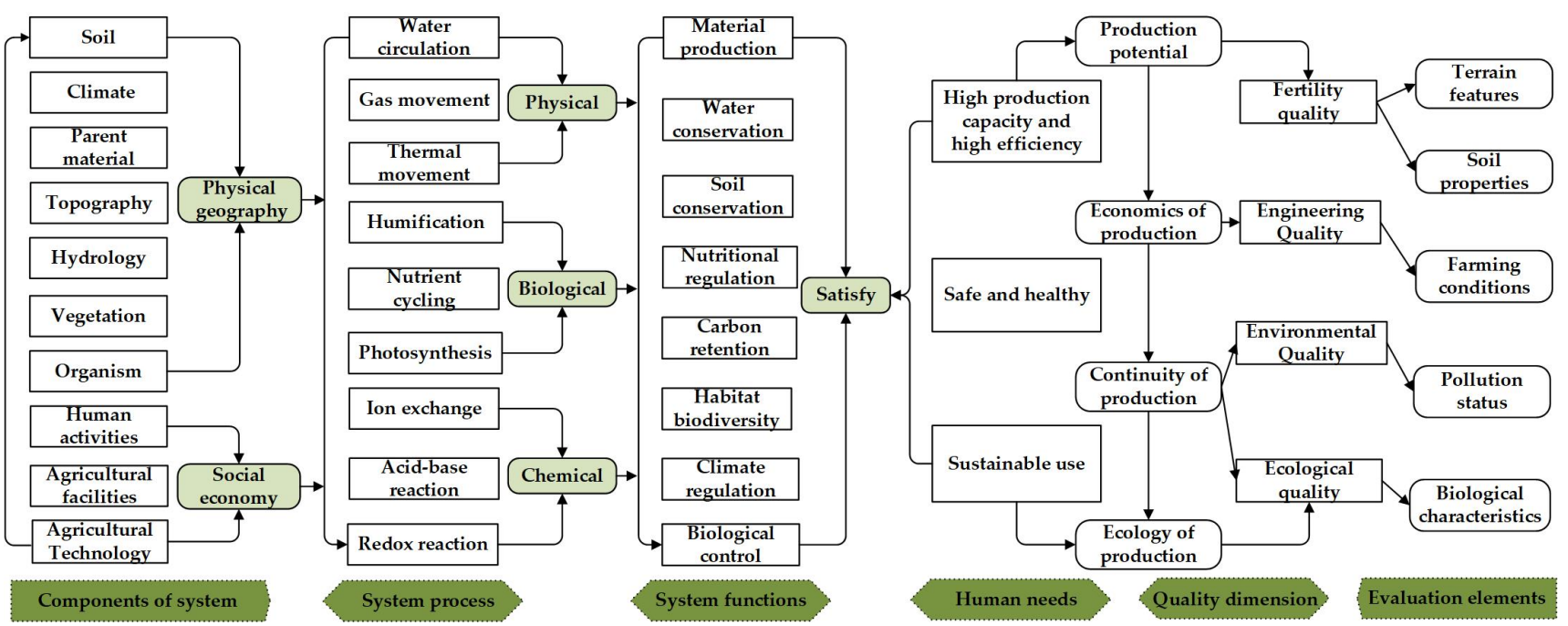

Figure 2. Theoretical framework for a farmland quality evaluation system at the field scale.

Table 1. Index system and index weight of CLQ evaluation at field scale.

\begin{tabular}{|c|c|c|c|c|c|}
\hline & Quality Dimensions & First-Level Indicators & Weight & Second-Level Indicators & Weight \\
\hline \multirow{16}{*}{ CLQ } & \multirow{9}{*}{ Soil fertility quality } & Topographic feature & 0.08 & Field slope & 1 \\
\hline & & \multirow{8}{*}{ Soil property } & \multirow{8}{*}{0.6} & Effective soil thickness & 0.17 \\
\hline & & & & Organic content & 0.16 \\
\hline & & & & Topsoil texture & 0.14 \\
\hline & & & & Soil profile pattern & 0.14 \\
\hline & & & & Gravel content & 0.12 \\
\hline & & & & Soil nutrient element $(\mathrm{N}, \mathrm{P}, \mathrm{K})$ & 0.11 \\
\hline & & & & Soil pH & 0.09 \\
\hline & & & & Soil agglomeration & 0.07 \\
\hline & \multirow{5}{*}{ Construction Quality } & \multirow{5}{*}{ Tillage condition } & \multirow{5}{*}{0.32} & The degree of Irrigation guarantee & 0.27 \\
\hline & & & & Drainage condition & 0.25 \\
\hline & & & & Field uniformity & 0.19 \\
\hline & & & & Accessibility of field roads & 0.17 \\
\hline & & & & Soil and water conservation function & 0.12 \\
\hline & Environmental quality & Pollution Status & - & Soil heavy mental elements & - \\
\hline & Ecological quality & Biological nature & - & Soil microbial biomass carbon & $\longrightarrow$ \\
\hline
\end{tabular}

\subsection{Methods Used to Evaluate CLQ}

Evaluations of agricultural production capacity, cultivated land potential, sustainability, grading, etc., are commonly used to assess CLQ [55-57]. Although different evaluation factors affect the quality of cultivated land at the same time, it does not mean that the CLQ index is acquired by their simple addition because some factors have a limiting effect [44]. Most indicators of topographical characteristics and soil properties are relatively stable and are unlikely to change significantly over the short term. The infrastructure associated with cultivated land also tends to be stable, but the organisms or animals in a soil can indirectly restrict crop yields by changing the physical and chemical properties of the soil. Furthermore, although heavy metal elements do not reduce crop yields within a limited concentration range, they can have an impact on crop quality and harm human health [58], which would restrict the sustainable use of cultivated land. This study regarded relatively stable soil fertility as the core quality of the cultivated land in the experimental area, engineering quality as its basic quality, and environmental and ecological quality as its restrictive qualities. A comprehensive algorithm was utilized to make an integrated evaluation of CLQ. First, the topographical characteristics and soil property scores of each evaluation unit in the experimental area were calculated using the weighted sum method in order to obtain the soil fertility quality index. The engineering quality index 
was calculated using the weighted sum method and the farming condition scores and the " $1+X$ " cumulative model was used to obtain the environmental quality coefficient. Then, the ecological quality coefficient and the environmental quality coefficient were used to modify the sum of the soil fertility quality and the engineering quality index to obtain the final CLQ index. The specific calculation processes were as follows:

\subsubsection{Soil Fertility Quality Index}

The weighted summation method was adopted; that is, the evaluation indicator and its weight were index-integrated to determine the topographical characteristics and soil property scores. Then the two were added together to calculate the soil fertility quality index. The formulae are as follows:

$$
\begin{gathered}
G_{i}=\sum_{j=1}^{n} A_{i j} B_{i j}(i, j=1,2,3 \ldots) \\
S_{i}=\sum_{j=1}^{n} M_{i j} N_{i j}(i, j=1,2,3 \ldots) \\
L_{i}=G_{i} W_{G}+S_{i} W_{S}
\end{gathered}
$$

where $G_{i}$ and $S_{i}$ are the topographic and soil property scores of the $i^{\text {th }}$ unit, respectively; $A_{i j}$ and $M_{i j}$ are the $\mathrm{j}^{\text {th }}$ second-level indicators for the topographic and soil property scores for the $\mathrm{i}^{\text {th }}$ unit, respectively; $B_{i j}$ and $N_{i j}$ are the indicator weights of the $\mathrm{j}^{\text {th }}$ second-level topographic and soil property scores of the $i^{\text {th }}$ unit, respectively; $n$ is the number of evaluation indicators; $L_{i}$ is the soil fertility quality index of the $i^{\text {th }}$ unit; $W_{G}$ is the top-level indicator weight for topography; and $W_{S}$ is the first-level indicator weight for soil property.

\subsubsection{Engineering Quality Index}

The weighted sum method was used to determine the score for farming conditions, which was then used to determine the engineering quality index. The formulae used were as follows:

$$
\begin{gathered}
C_{i}=\sum_{j=1}^{n} X_{i j} Y_{i j}(i, j=1,2,3 \ldots) \\
P_{i}=C_{i} W_{C}
\end{gathered}
$$

where $C_{i}$ represents the farming condition score of the $\mathrm{i}^{\text {th }}$ unit; $X_{i j}$ and $Y_{i j}$ are the corresponding scores and weights of the $j^{\text {th }}$ second-level indicator for the farming condition elements in the $\mathrm{i}^{\text {th }}$ unit, respectively; $P_{i}$ is the engineering quality index for the $\mathrm{i}^{\text {th }}$ unit; and $W_{C}$ is the weight of the first-level indicator for engineering quality.

\subsubsection{Environmental Quality Factor}

When CLQ is evaluated, the environmental quality coefficient adopts the accumulation model " $1+X$ ", and unpolluted cultivated land has a value of " 1 ", that is, the soil environmental quality coefficient $=1+$ the pollution status score.

\subsubsection{Ecological Quality Coefficient}

The formula is as follows:

$$
B_{i}=K_{i} / 100(i=1,2,3 \ldots)
$$

where $K_{i}$ is the comprehensive score for the biological characteristics of each field and $B_{i}$ is the ecological quality coefficient of the $\mathrm{i}^{\text {th }}$ unit.

\subsubsection{CLQ Index}

When the continuous product method is used, the sum of the soil fertility quality and engineering quality indexes is considered to be the natural quality of the cultivated land. 
Then, the environmental quality coefficient and ecological quality coefficient are used to revise the natural quality index to acquire the CLQ index.

$$
Q_{i}=\left(L_{i}+P_{i}\right) \times H_{i} \times B_{i}
$$

where $Q_{i}$ is the CLQ index of the $\mathrm{i}^{\text {th }}$ unit.

\subsection{Indicator Grading and Weight}

This study was based on the relevant technical standards in "Agricultural Land Quality Classification Regulations" (GB/T 28407-2012), "Agricultural Land Classification Regulations" (GB/T 28405-2012), and "Soil Environmental Quality Standards" (GB 156181995) to determine the level of the indicator. At the same time, we applied the analytic hierarchy process (AHP), and determined the final weights of the indicators based on the actual conditions of the test area, relevant literature values, and expert opinions (Table 1).

\subsection{Classification of the CLQ Index}

The equal spacing method divides the CLQ index into four classes: excellent (75-100), good (50-75), medium (25-50), and low (0-25), which correspond to level 1, level 2, level 3, and level 4 , respectively.

\section{Results}

\subsection{Comparison of the CLQ Evaluation Results before and after the Experimental Treatments}

The above-mentioned evaluation indicators and evaluation methods were used to evaluate the quality of the cultivated land before and after applying the different high-quality cultivated layers in the experimental area. The average quality levels of the cultivated land in the experimental area after the experiment increased by 0.63 compared to before the experiment (Table 2) and the average index increased by 30.63. The CLQ improvement after the experiment is shown in Figure 3. A total of $10,720.38 \mathrm{~m}^{2}$ of cultivated land $(62.95 \%$ of the total area) improved by one level. The four main indexes for the land generally advanced from level 3 to level 2 after the high-quality cultivation layers had been constructed. Although the quality of $10,547.61 \mathrm{~m}^{2}$ of cultivated land in the test area did not change after the different experimental treatments, its index significantly increased, which meant that the CLQ improved in the test area after the experiment. This showed that the construction of a high-quality tillage layer significantly improved CLQ.

Table 2. Comparison of CLQ evaluation results before and after the experiment in the test area.

\begin{tabular}{ccccccc}
\hline & $\begin{array}{c}\text { Average } \\
\text { Level }\end{array}$ & $\begin{array}{c}\text { Average } \\
\text { Index }\end{array}$ & $\begin{array}{c}\text { Soil Fertility Quality } \\
\text { Average Index }\end{array}$ & $\begin{array}{c}\text { Engineering Quality } \\
\text { Average Index }\end{array}$ & $\begin{array}{c}\text { Environmental Quality } \\
\text { Average Coefficient }\end{array}$ & $\begin{array}{c}\text { Ecological Quality } \\
\text { Average Coefficient }\end{array}$ \\
\hline $\begin{array}{c}\text { CLQ in the } \\
\text { test area } \\
\text { before the test } \\
\begin{array}{c}\text { CLQ in the } \\
\text { test area after } \\
\text { the test }\end{array}\end{array}$ & 3.00 & 27.8 & 39.11 & 30.39 & 1.00 & 0.40 \\
\hline
\end{tabular}

Table 3 shows the evaluation results of various quality dimensions before and after the soil layer experiment. The average index score for soil fertility quality after the construction of the high-quality tillage layers increased by 5.16 compared to before the test, the average coefficient for ecological quality rose by 0.31 , but the engineering quality index and the environmental quality coefficient did not change. Therefore, the CLQ before and after the experiment was mainly affected by soil fertility and ecological quality. The cultivated soil layer in the test area before the test was very thin, which meant that crop root growth and soil moisture storage capacity were low. The soil organic matter content and soil fertility were also very low. The alkali-hydrolyzed nitrogen was $16.71 \mathrm{mg} / \mathrm{kg}$ on average, the available phosphorus was $1.5 \mathrm{mg} / \mathrm{kg}$, and the available potassium was $38.16 \mathrm{mg} / \mathrm{kg}$. 
These data showed that the soils were classified as deficient according to the nutrient grading standard. The soil gravel content was high because the test area is located in a hilly area. A large amount of gravel remained after the soil layer treatments. Therefore, the land was prone to erosion, which would seriously affect the utilization and production characteristics of the cultivated land. Furthermore, the soil micro-aggregate levels were low, soil particle aggregation was poor, and soil micro-aggregate stability was weak. The $\mathrm{pH}$ of the soil was between 8.17 and 8.54 , which is slightly alkaline.
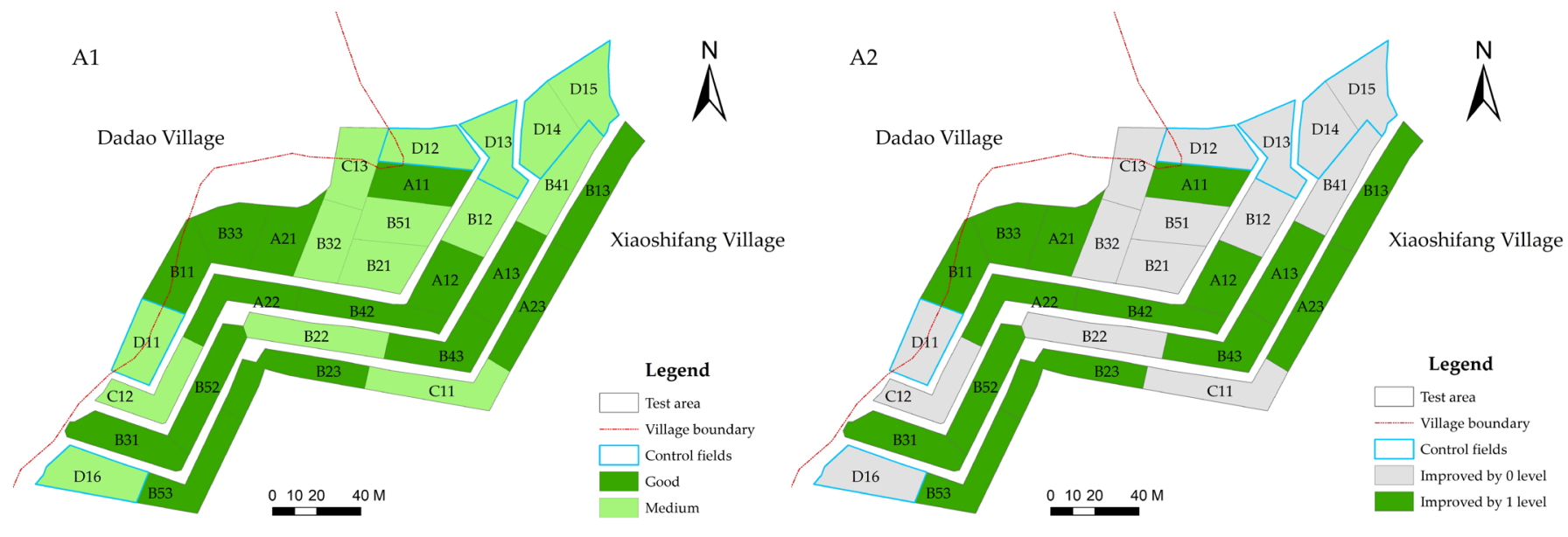

Figure 3. (A1) is the current state map showing the quality of the cultivated land after construction. (A2) is the quality improvement map for the cultivated land before and after the construction test.

Table 3. Evaluation results for the various quality dimensions before and after the experiment.

\begin{tabular}{|c|c|c|c|c|c|c|c|c|c|c|}
\hline FN & $\begin{array}{l}\text { SFQI } \\
\text { (B) }\end{array}$ & $\begin{array}{c}\text { SFQI } \\
\text { (A) }\end{array}$ & $\begin{array}{c}\text { EQI } \\
(\mathrm{A} / \mathrm{B})\end{array}$ & $\begin{array}{l}\text { EQC } \\
(\mathrm{A} / \mathrm{B})\end{array}$ & $\begin{array}{c}\text { EMC } \\
\text { (B) }\end{array}$ & $\begin{array}{c}\text { EMC } \\
\text { (A) }\end{array}$ & $\begin{array}{l}\text { CLQ Index } \\
\text { (B) }\end{array}$ & $\begin{array}{l}\text { CLQ Index } \\
\text { (A) }\end{array}$ & $\begin{array}{l}\text { The CLQ } \\
\text { (B) Level }\end{array}$ & $\begin{array}{l}\text { The CLQ } \\
\text { (A) Level }\end{array}$ \\
\hline A11 & 39.02 & 49.04 & 30.53 & 1.00 & 0.40 & 0.90 & 27.82 & 71.62 & Medium & Good \\
\hline A12 & 39.02 & 48.74 & 30.48 & 1.00 & 0.40 & 0.90 & 27.80 & 71.30 & Medium & Good \\
\hline A13 & 39.02 & 44.18 & 30.43 & 1.00 & 0.40 & 0.70 & 27.78 & 52.22 & Medium & Good \\
\hline A21 & 39.02 & 50.36 & 30.59 & 1.00 & 0.40 & 0.90 & 27.84 & 72.85 & Medium & Good \\
\hline A22 & 39.02 & 53.36 & 29.93 & 1.00 & 0.40 & 0.90 & 27.58 & 74.96 & Medium & Good \\
\hline A23 & 39.56 & 50.84 & 30.43 & 1.00 & 0.40 & 0.70 & 27.99 & 56.89 & Medium & Good \\
\hline B11 & 39.02 & 48.20 & 30.59 & 1.00 & 0.40 & 0.90 & 27.84 & 70.91 & Medium & Good \\
\hline B12 & 39.02 & 45.14 & 30.43 & 1.00 & 0.40 & 0.70 & 27.78 & 49.90 & Medium & Medium \\
\hline B13 & 39.02 & 43.22 & 30.59 & 1.00 & 0.40 & 0.90 & 27.84 & 66.43 & Medium & Good \\
\hline B21 & 39.02 & 43.22 & 30.43 & 1.00 & 0.40 & 0.70 & 27.78 & 48.55 & Medium & Medium \\
\hline B22 & 39.02 & 43.22 & 29.93 & 1.00 & 0.40 & 0.70 & 27.58 & 48.20 & Medium & Medium \\
\hline B23 & 39.02 & 44.06 & 29.93 & 1.00 & 0.40 & 0.90 & 27.58 & 66.59 & Medium & Good \\
\hline B31 & 39.02 & 45.14 & 30.59 & 1.00 & 0.40 & 0.70 & 27.84 & 53.01 & Medium & Good \\
\hline B32 & 39.02 & 44.18 & 30.53 & 1.00 & 0.40 & 0.70 & 27.82 & 49.30 & Medium & Medium \\
\hline B33 & 39.02 & 48.20 & 30.59 & 1.00 & 0.40 & 0.90 & 27.84 & 70.91 & Medium & Good \\
\hline B41 & 39.56 & 45.08 & 30.48 & 1.00 & 0.40 & 0.70 & 28.02 & 49.89 & Medium & Medium \\
\hline B42 & 39.56 & 46.82 & 29.87 & 1.00 & 0.40 & 0.70 & 27.77 & 53.68 & Medium & Good \\
\hline B43 & 39.02 & 45.38 & 30.48 & 1.00 & 0.40 & 0.70 & 27.80 & 53.10 & Medium & Good \\
\hline B51 & 39.56 & 41.30 & 30.48 & 1.00 & 0.40 & 0.70 & 28.02 & 47.25 & Medium & Medium \\
\hline B52 & 39.02 & 42.14 & 30.53 & 1.00 & 0.40 & 0.90 & 27.82 & 65.41 & Medium & Good \\
\hline B53 & 39.02 & 40.70 & 29.87 & 1.00 & 0.40 & 0.90 & 27.56 & 63.51 & Medium & Good \\
\hline C11 & 39.02 & 44.06 & 29.87 & 1.00 & 0.40 & 0.70 & 27.56 & 48.75 & Medium & Medium \\
\hline $\mathrm{C} 12$ & 39.56 & 43.22 & 29.98 & 1.00 & 0.40 & 0.70 & 27.82 & 48.24 & Medium & Medium \\
\hline $\mathrm{C} 13$ & 39.02 & 44.06 & 30.64 & 1.00 & 0.40 & 0.70 & 27.87 & 49.29 & Medium & Medium \\
\hline
\end{tabular}

A: After; B: Before; Field Number (FN); Soil Fertility Quality Index (SFQI); Engineering Quality Index (EQI); Environmental Quality Coefficient (EQC); Ecological Mass Coefficient (EMC). 
The main reason for constructing the high-quality farming layers was to improve the soil. Therefore, the farming conditions were not affected. Furthermore, the engineering quality of the cultivated land in the experimental test area was high with an average engineering quality index of 30.39. The average score for farming conditions was 94.97 and $24 \%$ of the cultivated fields were relatively similar. Furthermore, $76 \%$ of the cultivated fields were rectangular in shape. Fields that are rectangular or close to rectangular are more easily managed. The field roads in the test area greatly improved after the implementation of the field road project. In addition, the sloping land was converted into terraces in the test area. This conversion included the construction of horizontal terraces, terraced drainage ditches, U-shaped canals, and cutoff ditches. Mortar-filled stone embankments were established beside the cultivated fields to protect the cultivated land from erosion, field ridges were constructed in the landslide areas of the lower fields, and reservoirs and rainwater collection ponds were created in areas with large water catchments. These prevented water and soil erosion, which improved the utilization of water and soil resources.

Although the high-quality cultivation layer experiment changed the heavy metal contents in the soil, the environmental quality of the cultivated land did not decrease because the environmental quality coefficient for the cultivated land before and after the test was still 1, i.e., there was no heavy metal pollution. Before the experiment, the average $\mathrm{As}, \mathrm{Cr}, \mathrm{Cd}, \mathrm{Pb}$, and $\mathrm{Hg}$ contents were $6.28 \mathrm{mg} / \mathrm{kg}, 120.97 \mathrm{mg} / \mathrm{kg}, 0.12 \mathrm{mg} / \mathrm{kg}$, $15.19 \mathrm{mg} / \mathrm{kg}$, and $0.06 \mathrm{mg} / \mathrm{kg}$, respectively, whereas, after the experiment, the As, $\mathrm{Cr}$, $\mathrm{Cd}, \mathrm{Pb}$, and $\mathrm{Hg}$ contents were $7.83 \mathrm{mg} / \mathrm{kg}, 84.72 \mathrm{mg} / \mathrm{kg}, 0.11 \mathrm{mg} / \mathrm{kg}, 20.44 \mathrm{mg} / \mathrm{kg}$, and $0.03 \mathrm{mg} / \mathrm{kg}$, respectively, which were lower than the secondary standard values given in the Environmental Quality Standard (GB 15618-1995). Before the experiment, the average coefficient of ecological quality for the cultivated land was 0.4 , which can be classified as a low ecological quality level. The average soil microbial biomass carbon content was $18.23 \mathrm{mg} / \mathrm{kg}$ and ranged from $6.95 \mathrm{mg} / \mathrm{kg}$ to $29.46 \mathrm{mg} / \mathrm{kg}$, which meant that the fields had a low soil microbial biomass carbon content and the soil had poor microbial characteristics. After the experiment, the average ecological quality coefficient of the cultivated land was 0.78 , which is a relatively high ecological quality level. The average soil microbial biomass carbon content was $300.60 \mathrm{mg} / \mathrm{kg}$ and ranged from $243 \mathrm{mg} / \mathrm{kg}$ to $364 \mathrm{mg} / \mathrm{kg}$. Furthermore, the area of land with values above $300 \mathrm{mg} / \mathrm{kg}$ accounted for $41.87 \%$ of the total area. After the experiment, the soil microbial characteristics of the cultivated land were relatively strong and the soil ecological environment was conducive to microbial growth. These improvements increased the effective transformation of soil nutrients.

\subsection{Comparison of the CLQ Evaluation Results for the Different Experimental Treatments}

The results for the different experimental treatments and the individual indexes are shown as weighted averages. These were then used to obtain the CLQ indexes and levels for the eight experimental treatments (Table 4). The index levels of the cultivated land after each treatment ranged between good and medium. The average levels for the A1 and A2 treatments were the highest and they were classified as good. The B1 treatment level averaged 2.31 and the lowest level for the $\mathrm{C} 1$ treatment (control) was medium. The B2, B3, B4, and B5 treatment levels were slightly lower than the B1 treatment but higher than $\mathrm{C} 1$ treatment with a ranking order of $\mathrm{B} 5>\mathrm{B} 3>\mathrm{B} 4>\mathrm{B} 2$. The average index for the A2 treatment was the highest at 67.91 followed A1 at 64.72 , but the average index for the $\mathrm{C} 1$ treatment was lowest at 48.77. The differences in the levels and indexes among the treatments were mainly due to the soil fertility and ecological quality dimensions. The A2 treatment had the highest soil fertility quality average index (51.48), followed by A1 at 47.24. The lowest was the B5 treatment at 41.38. The A1, A2, B1, and B5 treatments recorded the highest average ecological quality coefficients at 0.83 . Furthermore, after the treatments, the soil microbial biomass carbon content was higher and the microbial characteristics were stronger than before the experiment. 
Table 4. Evaluation results for CLQ after the various experimental treatments.

\begin{tabular}{ccccccc}
\hline ET & $\begin{array}{c}\text { Average Level } \\
\text { of CLQ }\end{array}$ & $\begin{array}{c}\text { Average CLQ } \\
\text { Index }\end{array}$ & ASFQI & AEQI & AEQC1 & AEQC2 \\
\hline A1 & 2.00 & 64.72 & 47.24 & 30.48 & 1.00 & 0.83 \\
A2 & 2.00 & 67.91 & 51.48 & 30.32 & 1.00 & 0.83 \\
B1 & 2.31 & 62.80 & 45.48 & 30.54 & 1.00 & 0.83 \\
B2 & 2.65 & 54.80 & 43.52 & 30.08 & 1.00 & 0.77 \\
B3 & 2.33 & 57.69 & 45.83 & 30.57 & 1.00 & 0.77 \\
B4 & 2.34 & 52.18 & 45.73 & 30.29 & 1.00 & 0.70 \\
B5 & 2.32 & 58.93 & 41.38 & 30.29 & 1.00 & 0.83 \\
C1 & 3.00 & 48.77 & 43.80 & 30.16 & 1.00 & 0.70 \\
\hline
\end{tabular}

Experimental Treatment (ET); Average Soil Fertility Quality Index (ASFQI); Average Engineering Quality Index (AEQI); Average Environmental Quality Coefficient (AEQC1); Average Ecological Quality Coefficient (AEQC2).

The cultivated land quality index for each field in the experimental area under the different treatments is shown in Figure 4. It shows that each field plot had a different CLQ index and there were differences between fields that had been subjected to the same experimental treatment. Among them, field A22, which was subjected to the A2 treatment, had the highest quality index and was classified as the second-level cultivated land by the CLQ index. A21 was slightly lower than A22, but was also second-level cultivated land. The organic matter contents were highest in the fields subjected to the A2 treatment, with an average content of more than $2 \%$. The organic matter content in the A22 field was $3.1 \%$. In addition, the soil nutrient contents of the A2 treatment fields were higher than the average for the test area. They also had relatively small gravel contents, better soil agglomeration, and higher soil microbial biomass carbon contents. Therefore, the application of woody peat when constructing high-quality farming layers can significantly increase soil organic matter content and improve soil particle agglomeration, soil properties, and soil fertility. The results also showed that the A2 test treatment with woody peat and bio-stimulating regulator II effectively enhanced cultivated land quality to a greater extent than the other experimental treatments. After the experiment, the soil organic matter and nutrient contents soil particle agglomeration had significantly increased, which would indirectly boost CLQ.

\subsection{Influence of the Different Experimental Treatments on Millet Yield}

The average yield for each field was obtained by taking an average of the yields from the three plots in each field. The value was then converted into the millet yield per hectare. The average millet yields for the three replicates were used to obtain the millet yields for the eight test treatments. Figure 5 shows that the millet yield ranking after each experimental treatment was $\mathrm{A} 2>\mathrm{A} 1>\mathrm{B} 1>\mathrm{B} 5>\mathrm{B} 3>\mathrm{B} 2>\mathrm{B} 4$. The $\mathrm{A} 1$ and $\mathrm{A} 2$ yields were higher than those of the other groups, and the A2 yield was the highest at $2538.46 \mathrm{~kg} / \mathrm{ha}$. The yields increased significantly compared to the control group (C1), with an average increase of $57.96 \%$. The B1, B2, B3, B4, and B5 crop yields were higher than C1. The B1 treatment showed the highest increase in output among the B treatments at $48.51 \%$, B4 had the lowest increase in output, at $1.59 \%$, and B2, B3, and B5, whose percentage increases were $4.07 \%$, $10.09 \%$, and $13.08 \%$, respectively, showed no significant difference in output. 


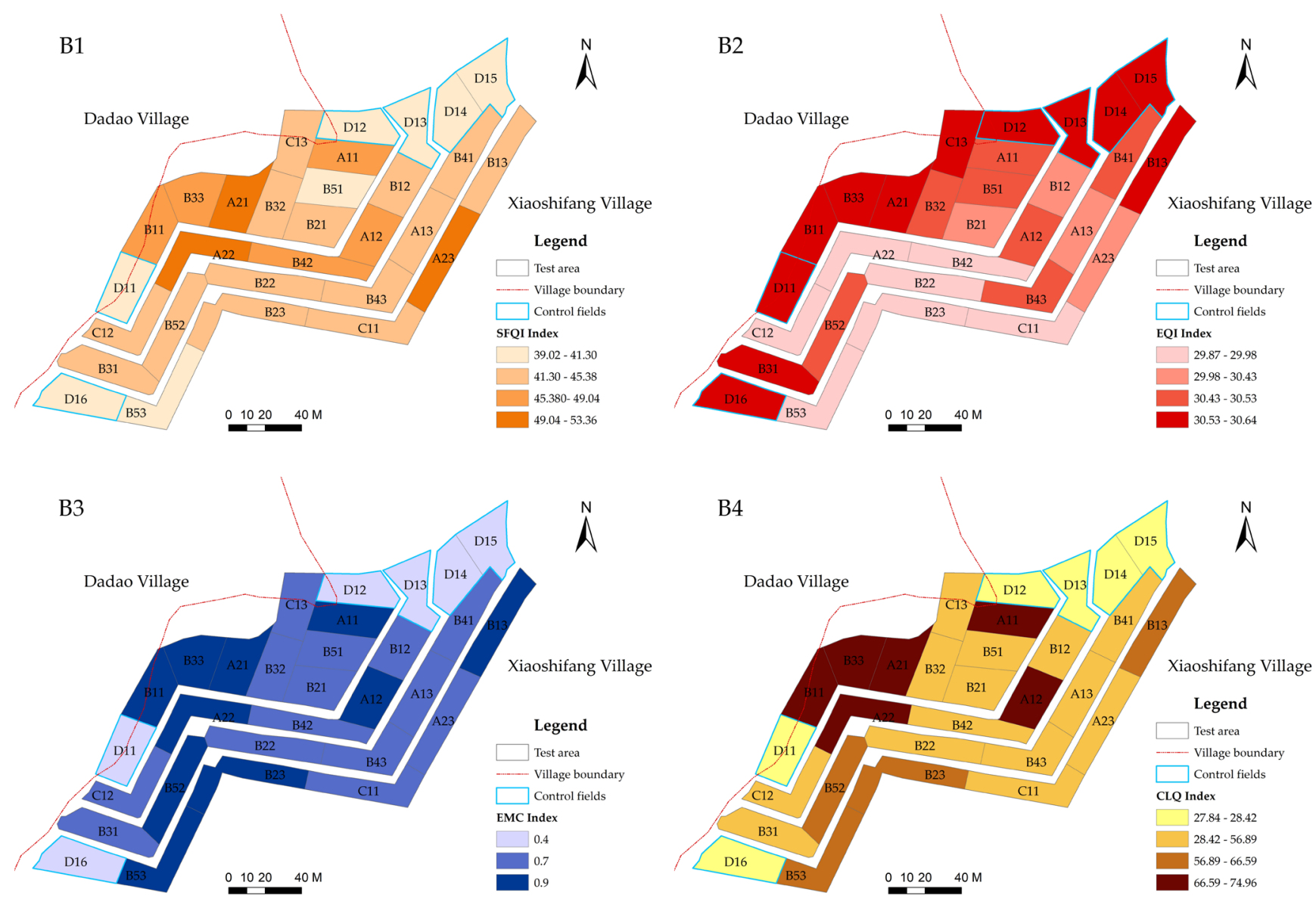

Figure 4. B1 is the map of the distribution of the soil fertility quality indexes for the different experimental treatments; $\mathbf{B} 2$ is the map of the distribution of the engineering quality indexes for the different experimental treatments; $\mathbf{B} 3$ is the map of the distribution of the ecological quality indexes for the different experimental treatments; $\mathbf{B} 4$ is the map of the distribution of the cropland quality indexes for the different experimental treatments.

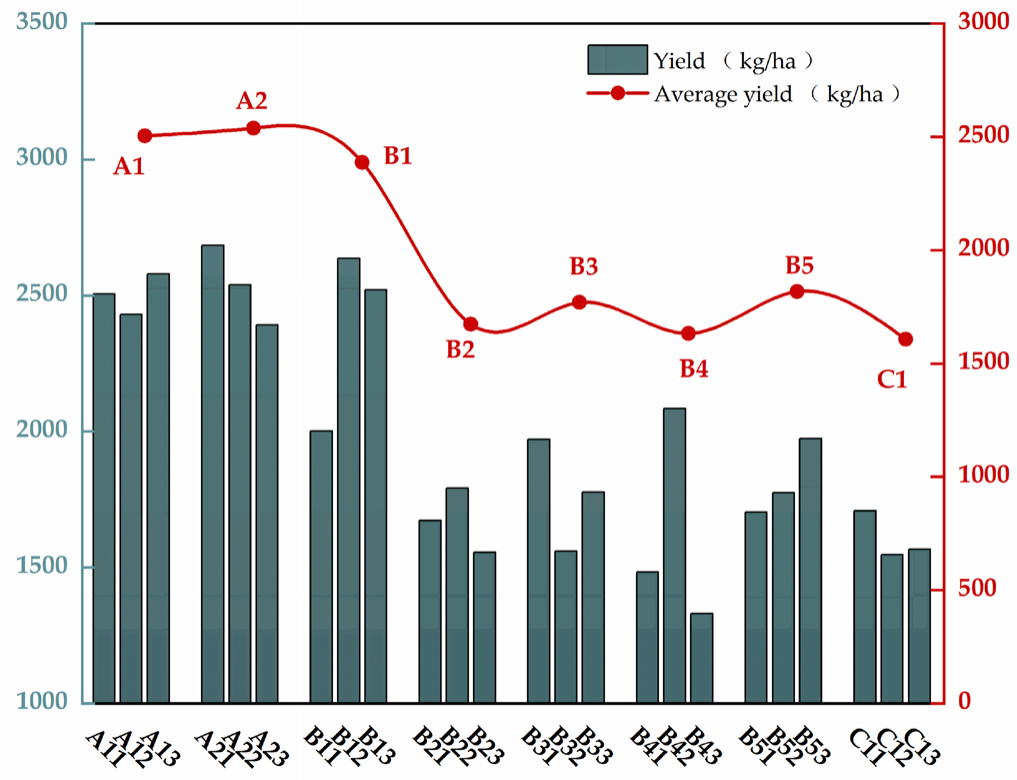

Figure 5. Crop yields under the different experimental treatments. 
The results showed that woody peat is rich in humic acid, which can stimulate the growth and development of crops, especially root growth and elongation. The addition of woody peat along with conventional fertilizer can promote the growth and development of crop roots and aerial parts and improve crop yields. In this study, the application of woody peat improved the physical and chemical properties of the soil and the ecological and environmental quality indicators. A comparative analysis of the treatment crop yields showed that woody peat improved crop yields when combined with a biological excitation regulator. The experimental results showed that the A2 treatment had the best effect because its millet yield was the highest and the yield increase effect was good. It produced the most significant improvements in soil organic matter content, effective soil nutrients, and soil microbial biomass carbon. These results demonstrated that woody peat, as an organic soil improver, improved soil quality and crop yield over the short term, considerably shortened cultivation time, and could be used to rapidly construct high-quality cultivation layers that improve the quality of cultivated land.

\section{Discussion}

During the implementation of CLBP, the natural resource endowment of newly reclaimed arable land is far inferior to the highquality arable land that has been occupied $[8,59]$. At the same time, the existing CLQ evaluation indicators are not accurately linked within a consistent conceptual framework [60], and the field-scale evaluation system does not consider the multiplicity of CLQ. To this end, the present study employed woody peat and other organic materials as the core to perform different methods of high quality farming layer construction experiments to help improve the CLQ. Most importantly, by analyzing the constituent elements, operation process, and functions of the cultivated land system, combined with the public's demand for cultivated land quality, we constructed a theoretical framework (Figure 1) and index system (Table 1). Moreover, by evaluating the impact of different test methods on the CLQ, the best test mode was determined. In particular, a CLQ evaluation system was established from the following four quality dimensions:

(1) The core component of a CLQ assessment is soil quality [39]. Field slope is the natural slope of cultivated land and its degree is closely related to the redistribution of materials, energy, and precipitation across cultivated land, and the degree of erosion and destruction [61]. These factors can reflect the soil and water conservation potential of cultivated land and maintain its ecological quality. Effective soil layer thickness, soil organic matter, soil $\mathrm{pH}$, soil texture and land configuration are the basic evaluation indexes for cultivated land soil quality [62-64] and can reflect the most basic natural conditions of cultivated land. In addition to these commonly used indexes of soil physical and chemical properties, we also supplemented the model with indexes for soil nutrient elements, gravel content, and soil aggregates, etc. Soil nutrient elements are necessary for crop growth and reflect soil fertility [65]. After the restoration and development of unused land, a large amount of debris and gravel will often remain in the soil, which will affect subsequent crop growth [34]. Soil aggregation degree represents the aggregation state of the soil particles (including soil micro-aggregates) [66]. Therefore, it is an index that is commonly used to measure soil corrosion resistance because the higher the degree of aggregation, the stronger the soil corrosion resistance.

(2) The Land Evaluation and Site Analysis System (LESA) developed by the USDA emphasizes the influence of cultivated land use conditions on CLQ [67]. Besides irrigation and drainage conditions, we also selected indexes such as field uniformity, field road accessibility, and water and soil conservation function. Water is one of the key factors that support the growth of food crops. Good irrigation and drainage conditions can maintain the balance of water and soil in farmland [68], and the tidier a field is, the easier it is to cultivate and manage the land [69]. Road accessibility also has an impact on agricultural production, mechanical farming, material transportation and land-use efficiency [70]. In addition, water and soil conservation projects can prevent and control soil erosion [33]. 
(3) The secondary index for pollution status is the soil heavy metals content because it directly reflects the environmental pollution of cultivated land and affects the food safety of cultivated land production [44]. Studies have shown that heavy metals, such as lead and chromium, can lead to the degradation of cultivated land quality [71]. In addition, metal elements also influence microbial activity in soil [58] and soil organisms and their processes have important impacts on soil health [72].

(4) The secondary index for biological characteristics is soil microbial carbon content. Soil microorganisms are the most active component of soil and can regulate and participate in various biochemical reaction processes in soil [73]. They are closely related to the formation and development of soil [74]. Soil microbial carbon content is often used to express microbial activities and a high microbial carbon content indicates that the cultivated soil environment is conducive to microbial growth and sustainable production $[75,76]$.

The evaluation results showed that the organic materials with woody peat as the core could significantly increase the content of soil organic matter, soil effective nutrients, and soil microbial biomass carbon, and improve the aggregation of soil particles, thereby improving the CLQ, when compared with traditional fertilization methods (Tables 2 and 3). A2 (woody peat + decomposed crop straw + biological stimulation regulator II + conventional fertilization) presented the best test effect among the examined treatments, and produced significant improvement in the comprehensive CLQ index (Table 4). The evaluation results of CLQ were also effectively verified by crop yield data (Figure 5). It must be noted that woody peat is rich in humic acid. Humic acid contains a variety of functional groups and has high biochemical activity, which can decompose minerals and fix soil nutrients [77]. Besides, woody peat also contains high humus and nutrients content. Upon incorporation into the soil, woody peat can quickly increase the total soil organic matter and nutrients contents, and provide sufficient nutrients for soil microbial activities [78]. In addition, woody peat has a good pore structure, which can improve soil texture to a certain extent [79]. It has been reported that incorporation of organic materials such as woody peat and decomposed straw into the soil increases the soil surface area, facilitating soil microbial activities [80]. The increase in soil microbial communities involved in nitrogen, phosphorus, and potassium cycles can further enhance soil effective nutrients content and soil microbial carbon content [81]. Thus, these factors simultaneously resolved the limiting elements of crop growth, thereby increasing crop yield.

In general, according to the principle of synergistic mechanism of soil organic mattersoil aggregates-biological activity, application of soil amendments with woody peat as the core could result in a high quality farming layer and rapidly improve CLQ. In addition, the CLQ evaluation method developed in this study compensated for the deficiencies in the field-scale CLQ evaluation, and addressing questions such as how to quickly improve the quality of the newly developed arable land under the CLBP and how the land improvement project can assist poverty alleviation development policy, etc., can have practical significance. Thus, the improved arable land can also be transferred out smoothly through the CLBP, which can not only help cities and developed areas to replenish high-quality arable land, but can also achieve a balance between the CLQ and guarantee their construction and development needs. However, this study did not explore the impacts of this technology on the quality of cultivated land on a time scale. In future, through the establishment of a CLQ monitoring system, the CLQ can be evaluated over a longer time period and the factors affecting the CLQ can be further revealed.

\section{Conclusions}

The theoretical framework of the CLQ evaluation system was established by analyzing the constituent elements of the cultivated land system. These elements were based on the operating process, functions of the cultivated land, and public demand for high quality cultivated land. The CLQ index was based on four quality dimensions, which were combined with the results from a land consolidation and development project and an experiment that investigated the characteristics of different high-quality farming layers. 
The data obtained were combined to create a set of index systems and methods for evaluating the quality of cultivated land at the field scale. The developed method for evaluating the quality of cultivated land can be used to rapidly improve the quality of newly developed cultivated land under the CLBP and can help land improvement projects contribute to poverty alleviation and development policy.

The CLQ index, crop yield, and attribute values for each soil property index were compared after different high-quality cultivation layers had been applied. The results showed that the A2 treatment (woody peat + decomposed crop straw + biological excitation regulator II + conventional fertilization) had the most effect and the land was classified as good. It also produced the highest crop yield, which was $57.96 \%$ higher than the control C1 yield. It also had the best improvement effect on soil organic matter content, soil effective nutrients, soil microbial biomass carbon, and soil particle aggregation status, which showed that the application of woody peat when constructing a high quality farming layer project can rapidly improve farmland quality. Finally, in future, the results from the experiments on the construction of high quality farming layers should be compared at different time scales, and a systematic discussion on the transformations of factors affecting the quality of farmland when applying a high quality cultivation layer should be performed, which could reveal the evolution and improvement mechanisms underlying the increases in farmland quality. Moreover, the evaluation indicators should be optimized, and a more operational, scientific, and reasonable evaluation system should be developed.

Author Contributions: Conceptualization, L.K., R.Z. and K.W.; methodology, L.K. and R.Z.; software, L.K.; validation, L.K., R.Z. and S.Z.; formal analysis, L.K.; investigation, L.K. and R.Z.; resources, K.W., Q.H.; data curation, L.K., R.Z. and S.Z.; writing-original draft preparation, L.K. and R.Z.; writing-review and editing, K.W., L.K. and Q.H.; visualization, L.K.; supervision, K.W., Q.H.; project administration, K.W.; funding acquisition, K.W. All authors have read and agreed to the published version of the manuscript.

Funding: This study was supported by the National Key R\&D Program of China (No. 2018YFE0107000).

Institutional Review Board Statement: Not applicable.

Data Availability Statement: The datasets used and/or analyzed during the current study are available from the corresponding author on reasonable request.

Acknowledgments: We are thankful for the research assistance from Xuemin, Liu. The insightful and constructive comments of the anonymous reviewers are appreciated.

Conflicts of Interest: The authors declare no conflict of interest.

\section{References}

1. Bai, Y.; Liu, M.; Yang, L. Calculation of ecological compensation standards for arable land based on the value flow of support services. Land 2021, 10, 719. [CrossRef]

2. Liang, S.-Y.; Lehmann, A.; Wu, K.-N.; Stahr, K. Perspectives of function-based soil evaluation in land-use planning in China. J. Soils Sedim. 2014, 14, 10-22. [CrossRef]

3. Heerink, N.; Qu, F.; Kuiper, M.; Shi, X.; Tan, S. Policy reforms, rice production and sustainable land use in China: A macro-micro analysis. Agric. Syst. 2007, 94, 784-800. [CrossRef]

4. Su, M.; Guo, R.; Hong, W. Institutional transition transition and implementation path for cultivated land protection in highly urbanized regions: A case study of Shenzhen, China. Land Use Policy 2019, 81, 493-501. [CrossRef]

5. Song, W.; Pijanowski, B.C. The effects of China's cultivated land balance program on potential land productivity at a national scale. Appl. Geogr. 2014, 46, 158-170. [CrossRef]

6. Chengchuang, Q.; Xiaomin, C.; Jiabao, Z.; Shuyin, F.; Jun, T.; Yueyuan, R.; Yinfang, Z.; Donghe, W.; Zhaoqiang, H.; Zhilong, Z. Techniques and effects of quickly constructing high-quality tillage layers for newly-cultivated arable land in red soil and paddy field based on woody peat and organic materials. J. Soil Water Conserv. 2018, 32, 134-140. [CrossRef]

7. Jin, H.; Zhong, Y.; Shi, D.; Li, J.; Lou, Y.; Li, Y.; Li, J. Quantifying the impact of tillage measures on the cultivated-layer soil quality in the red soil hilly region: Establishing the thresholds of the minimum data set. Ecol. Indic. 2021, 130, 108013. [CrossRef]

8. Bing, Y.; Kening, W.; Qin, H. Study on the effect of woody peat on the dry matter accumulation and yield of millet. Soil Fertil. Sci. China 2018, 2018, 102-108.

9. Tao, J.; Chen, J.; Du, S.Y.; Chen, X.; Li, S.Y.; Zhou, J. Soil organism diversity and functions in plastic shed and open field soils under different cultivation methods. Appl. Ecol. Environ. Res. 2021, 19, 2133-2150. [CrossRef] 
10. Ronga, D.; Mantovi, P.; Pacchioli, M.T.; Pulvirenti, A.; Bigi, F.; Allesina, G.; Pedrazzi, S.; Tava, A.; Dal Pra, A. Combined effects of dewatering, composting and pelleting to valorize and delocalize livestock manure, improving agricultural sustainability. Agronomy 2020, 10, 661. [CrossRef]

11. Adhikari, K.; Smith, D.R.; Collins, H.; Haney, R.L.; Wolfe, J.E. Corn response to selected soil health indicators in a Texas drought. Ecol. Indic. 2021, 125, 107482. [CrossRef]

12. Yang, T.; Siddique, K.H.M.; Liu, K. Cropping systems in agriculture and their impact on soil health-A review. Glob. Ecol. Conserv. 2020, 23, e01118. [CrossRef]

13. Lal, R. Soil health and carbon management. Food Energy Secur. 2016, 5, 212-222. [CrossRef]

14. Nunes, M.R.; Veum, K.S.; Parker, P.A.; Holan, S.H.; Karlen, D.L.; Amsili, J.P.; van Es, H.M.; Wills, S.A.; Seybold, C.A.; Moorman, T.B. The soil health assessment protocol and evaluation applied to soil organic carbon. Soil Sci. Soc. Am. J. 2021, 85, 1196-1213. [CrossRef]

15. Kennedy, N.; Edwards, S.; Clipson, N. Soil bacterial and fungal community structure across a range of unimproved and semi-improved upland grasslands. Microb. Ecol. 2005, 50, 463-473. [CrossRef] [PubMed]

16. Zhang, Z.; Shi, Z.; Yang, J.; Hao, B.; Hao, L.; Diao, F.; Wang, L.; Bao, Z.; Guo, W. A new strategy for evaluating the improvement effectiveness of degraded soil based on the synergy and diversity of microbial ecological function. Ecol. Indic. 2021, 120, 106917. [CrossRef]

17. Dietrich, S.T.; MacKenzie, M.D.; Battigelli, J.P.; Enterina, J.R. Building a better soil for upland surface mine reclamation in northern Alberta: Admixing peat, subsoil, and peat biochar in a greenhouse study with aspen. Can. J. Soil Sci. 2017, 97, 592-605. [CrossRef]

18. Edvardsson, J.; Rimkus, E.; Corona, C.; Simanauskiene, R.; Kazys, J.; Stoffel, M. Exploring the impact of regional climate and local hydrology on Pinus sylvestris L. growth variability-A comparison between pine populations growing on peat soils and mineral soils in Lithuania. Plant Soil 2015, 392, 345-356. [CrossRef]

19. Wakhid, N.; Hirano, T.; Okimoto, Y.; Nurzakiah, S.; Nursyamsi, D. Soil carbon dioxide emissions from a rubber plantation on tropical peat. Sci. Total Environ. 2017, 581, 857-865. [CrossRef]

20. Kang, Y.; Yamada, H.; Kyuma, K.; Hattori, T.; Kigasawa, S. Selenium in soil humic-acid. Soil Sci. Plant Nutr. 1991, 37, $241-248$. [CrossRef]

21. Chen, Z.; Shi, D. Spatial structure characteristics of slope farmland quality in plateau mountain area: A case study of Yunnan Province, China. Sustainability 2020, 12, 7230. [CrossRef]

22. Quandt, A.; Herrick, J.; Peacock, G.; Salley, S.; Buni, A.; Mkalawa, C.C.; Neff, J. A standardized land capability classification system for land evaluation using mobile phone technology. J. Soil Water Conserv. 2020, 75, 579-589. [CrossRef]

23. Qian, F.; Wang, W.; Wang, Q.; Lal, R. Implementing land evaluation and site assessment (LESA system) in farmland protection: A case-study in northeastern China. Land Degrad. Dev. 2021, 32, 2437-2452. [CrossRef]

24. Dumanski, J.; Pieri, C. Land quality indicators: Research plan. Agric. Ecosyst. Environ. 2000, 81, 93-102. [CrossRef]

25. Pretty, J.; Benton, T.G.; Bharucha, Z.P.; Dicks, L.V.; Flora, C.B.; Godfray, H.C.J.; Goulson, D.; Hartley, S.; Lampkin, N.; Morris, C.; et al. Global assessment of agricultural system redesign for sustainable intensification. Nat. Sustain. 2018, 1, 441-446. [CrossRef]

26. Li, L.; Niu, Y.; Ruan, Y.; DePauw, R.M.; Singh, A.K.; Gan, Y. Agronomic advancement in tillage, crop rotation, soil health, and genetic gain in durum wheat cultivation: A 17-year Canadian story. Agronomy 2018, 8, 193. [CrossRef]

27. Wang, J.; Lin, Y.; Glendinning, A.; Xu, Y. Land-use changes and land policies evolution in China's urbanization processes. Land Use Policy 2018, 75, 375-387. [CrossRef]

28. Lu, H.; Xie, H.; Lv, T.; Yao, G. Determinants of cultivated land recuperation in ecologically damaged areas in China. Land Use Policy 2019, 81, 160-166. [CrossRef]

29. Li, T.; Liu, Y.; Lin, S.; Liu, Y.; Xie, Y. Soil pollution management in China: A brief introduction. Sustainability 2019, 11, 556. [CrossRef]

30. Qijun, Y.; Kening, W.; Zhe, F.; Rui, Z.; Xiaodan, Z.; Xiaoliang, L. Soil quality assessment on large spatial scales: Advancement and revelation. Acta Pedol. Sin. 2020, 57, 565-578.

31. Bouma, J.; Finke, P.A.; Hoosbeek, M.R.; Breeuwsma, A. Soil and water quality at different scales: Concepts, challenges, conclusions and recommendations. Nutr. Cycl. Agroecosyst. 1998, 50, 5-11. [CrossRef]

32. Guanhua, W.; Kening, W.; Bing, Y.; Qijun, Y. Comparison of the evaluation methods of arable land quality in land consolidation project area-Taking Dehui as an example. Chin. J. Soil Sci. 2019, 50, 786-793. [CrossRef]

33. Kening, W.; Rui, Z.; Huafu, Z. Thoughts on the investigation and evaluation of cultivated land quality in China. China Land 2018, 2018, 19-20. [CrossRef]

34. Rui, Z.; Kening, W.; Tianqian, C. Optimization of cultivated land quality evaluation for land consolidation. Chin. J. Ecol. 2019, 38, 2433-2441. [CrossRef]

35. Bedada, W.; Lemenih, M.; Karltun, E. Soil nutrient build-up, input interaction effects and plot level N and P balances under long-term addition of compost and NP fertilizer. Agric. Ecosyst. Environ. 2016, 218, 220-231. [CrossRef]

36. Ouyang, W.; Wei, X.; Hao, F. Long-term soil nutrient dynamics comparison under smallholding land and farmland policy in northeast of China. Sci. Total Environ. 2013, 450, 129-139. [CrossRef] [PubMed]

37. Peng, J.; Wen, L.; Fu, L.; Yi, M. Total factor productivity of cultivated land use in China under environmental constraints: Temporal and spatial variations and their influencing factors. Environ. Sci. Pollut. Res. 2020, 27, 18443-18462. [CrossRef] 
38. Sheng, Y.; Liu, W.; Xu, H.; Gao, X. The spatial distribution characteristics of the cultivated land quality in the diluvial fan terrain of the arid region: A case study of Jimsar County, Xinjiang, China. Land 2021, 10, 896. [CrossRef]

39. Tan, Y.; Chen, H.; Lian, K.; Yu, Z. Comprehensive evaluation of cultivated land quality at county scale: A case study of Shengzhou, Zhejiang Province, China. Int. J. Environ. Res. Public Health 2020, 17, 1169. [CrossRef]

40. Steenwerth, K.; Belina, K.M. Cover crops enhance soil organic matter, carbon dynamics and microbiological function in a vineyard agroecosystem. Appl. Soil Ecol. 2008, 40, 359-369. [CrossRef]

41. Hargreaves, S.K.; DeJong, P.; Laing, K.; McQuail, T.; Van Eerd, L.L. Management sensitivity, repeatability, and consistency of interpretation of soil health indicators on organic farms in southwestern Ontario. Can. J. Soil Sci. 2019, 99, 508-519. [CrossRef]

42. Qun, W. On the quality, grade and price of cultivated land. J. Shandong Agric. Eng. Univ. 2002, 2002, 73-74. [CrossRef]

43. Bouma, J.; Batjes, N.H.; Groot, J.J.R. Exploring land quality effects on world food supply. Geoderma 1998, 86, 43-59. [CrossRef]

44. Zhao, C.; Zhou, Y.; Jiang, J.; Xiao, P.; Wu, H. Spatial characteristics of cultivated land quality accounting for ecological environmental condition: A case study in hilly area of northern Hubei province, China. Sci. Total Environ. 2021, $774,145765$. [CrossRef]

45. Zhu, Y.; Zhou, X.; Gan, Y.; Chen, J.; Yu, R. Spatio-temporal differentiation and driving mechanism of the "resource curse" of the cultivated land in main agricultural production regions: A case study of Jianghan Plain, Central China. Int. J. Environ. Res. Public Health 2021, 18, 858. [CrossRef]

46. Fisher, B.; Turner, R.K.; Morling, P. Defining and classifying ecosystem services for decision making. Ecol. Econ. 2009, 68, 643-653. [CrossRef]

47. Vogel, H.-J.; Bartke, S.; Daedlow, K.; Helming, K.; Koegel-Knabner, I.; Lang, B.; Rabot, E.; Russell, D.; Stoessel, B.; Weller, U.; et al. A systemic approach for modeling soil functions. Soil 2018, 4, 83-92. [CrossRef]

48. Greiner, L.; Nussbaum, M.; Papritz, A.; Fraefel, M.; Zimmermann, S.; Schwab, P.; Gret-Regamey, A.; Keller, A. Assessment of soil multi-functionality to support the sustainable use of soil resources on the Swiss Plateau. Geoderma Reg. 2018, 14 , e00181. [CrossRef]

49. Vrebos, D.; Jones, A.; Lugato, E.; O’Sullivan, L.; Schulte, R.; Staes, J.; Meire, P. Spatial evaluation and trade-off analysis of soil functions through Bayesian networks. Eur. J. Soil Sci. 2021, 72, 1575-1589. [CrossRef]

50. Liu, H.; Zhou, Y. Farmers' cognition and behavioral response towards cultivated land quality protection in Northeast China. Sustainability 2018, 10, 1905. [CrossRef]

51. Brevik, E.C.; Steffan, J.J.; Rodrigo-Comino, J.; Neubert, D.; Burgess, L.C.; Cerda, A. Connecting the public with soil to improve human health. Eur. J. Soil Sci. 2019, 70, 898-910. [CrossRef]

52. Minami, K. Soil and humanity: Culture, civilization, livelihood and health. Soil Sci. Plant Nutr. 2009, 55, 603-615. [CrossRef]

53. Ruf, T.; Makselon, J.; Udelhoven, T.; Emmerling, C. Soil quality indicator response to land-use change from annual to perennial bioenergy cropping systems in Germany. Glob. Chang. Biol. Bioenergy 2018, 10, 444-459. [CrossRef]

54. Belcher, K.W.; Boehm, M.M.; Zentner, R.P. The economic value of soil quality under alternative management in the Canadian prairies. Can. J. Agric. Econ. 2003, 51, 175-196. [CrossRef]

55. Lin, L.; Ye, Z.; Gan, M.; Shahtahmassebi, A.R.; Weston, M.; Deng, J.; Lu, S.; Wang, K. Quality perspective on the dynamic balance of cultivated land in Wenzhou, China. Sustainability 2017, 9, 95. [CrossRef]

56. Wang, H.; Li, W.; Zhu, C.; Tang, X. Analysis of heavy metal pollution in cultivated land of different quality grades in Yangtze River Delta of China. Int. J. Environ. Res. Public Health 2021, 18, 9876. [CrossRef]

57. Zhao, R.; Wu, K.; Li, X.; Gao, N.; Yu, M. Discussion on the unified survey and evaluation of cultivated land quality at county scale for China's 3rd national land survey: A case study of Wen County, Henan Province. Sustainability 2021, 13, 2513. [CrossRef]

58. Mamehpour, N.; Rezapour, S.; Ghaemian, N. Quantitative assessment of soil quality indices for urban croplands in a calcareous semi-arid ecosystem. Geoderma 2021, 382, 114781. [CrossRef]

59. Deng, Z.; Zhao, Q.; Bao, H.X.H. The impact of urbanization on farmland productivity: Implications for China's requisitioncompensation balance of farmland policy. Land 2020, 9, 311. [CrossRef]

60. Thoumazeau, A.; Bessou, C.; Renevier, M.-S.; Trap, J.; Marichal, R.; Mareschal, L.; Decaens, T.; Bottinelli, N.; Jaillard, B.; Chevallier, T.; et al. Biofunctool (R): A new framework to assess the impact of land management on soil quality. Part A: Concept and validation of the set of indicators. Ecol. Indic. 2019, 97, 100-110. [CrossRef]

61. Wilson, G.A. The spatiality of multifunctional agriculture: A human geography perspective. Geoforum 2009, 40, 269-280. [CrossRef]

62. Haydu-Houdeshell, C.-A.; Graham, R.C.; Hendrix, P.F.; Peterson, A.C. Soil aggregate stability under chaparral species in southern California. Geoderma 2018, 310, 201-208. [CrossRef]

63. Reinhart, K.O.; Vermeire, L.T. Soil aggregate stability and grassland productivity associations in a northern mixed-grass prairie. PLoS ONE 2016, 11, e0160262. [CrossRef] [PubMed]

64. Tung Gia, P.; Hung Trong, N.; Kappas, M. Assessment of soil quality indicators under different agricultural land uses and topographic aspects in Central Vietnam. Int. Soil Water Conserv. Res. 2018, 6, 280-288. [CrossRef]

65. Kuscu, I.S.K.; Cetin, M.; Yigit, N.; Savaci, G.; Sevik, H. Relationship between enzyme activity (urease-catalase) and nutrient element in soil use. Pol. J. Environ. Stud. 2018, 27, 2107-2112. [CrossRef]

66. Palojarvi, A.; Nuutinen, V. The soil quality concept and its importance in the study of Finnish arable soils. Agric. Food Sci. Finl. 2002, 11, 329-342. [CrossRef] 
67. Tyler, M.; Hunter, L.; Steiner, F. use of agricultural land evaluation and site assessment in Whitman County, Washington, USA. Environ. Manag. 1987, 11, 407-412. [CrossRef]

68. Sun, J.; Li, Y.P.; Suo, C.; Liu, Y.R. Impacts of irrigation efficiency on agricultural water-land nexus system management under multiple uncertainties-A case study in Amu Darya River basin, Central Asia. Agric. Water Manag. 2019, 216, 76-88. [CrossRef]

69. Liu, Y.; Xue, J.; Gui, D.; Lei, J.; Sun, H.; Lv, G.; Zhang, Z. Agricultural oasis expansion and its impact on oasis landscape patterns in the southern margin of Tarim basin, Northwest China. Sustainability 2018, 10, 1957. [CrossRef]

70. Castella, J.C.; Manh, P.H.; Kam, S.P.; Villano, L.; Tronche, N.R. Analysis of village accessibility and its impact on land use dynamics in a mountainous province of northern Vietnam. Appl. Geogr. 2005, 25, 308-326. [CrossRef]

71. Wang, X.; Xin, L.; Tan, M.; Li, X.; Wang, J. Impact of spatiotemporal change of cultivated land on food-water relations in China during 1990-2015. Sci. Total Environ. 2020, 716, 137119. [CrossRef] [PubMed]

72. Fierer, N.; Wood, S.A.; de Mesquita, C.P.B. How microbes can, and cannot, be used to assess soil health. Soil Biol. Biochem. 2021, 153, 108111. [CrossRef]

73. Chen, H.; Yao, J.; Wang, F.; Gyula, Z. Study of the Influence of different diphenol compounds on soil microbial activity by microcalorimetry. Chin. J. Chem. 2009, 27, 2125-2129. [CrossRef]

74. Li, Z.; Li, D.; Ma, L.; Yu, Y.; Zhao, B.; Zhang, J. Effects of straw management and nitrogen application rate on soil organic matter fractions and microbial properties in North China Plain. J. Soils Sedim. 2019, 19, 618-628. [CrossRef]

75. Upton, R.N.; Bach, E.M.; Hofmockel, K.S. Spatio-temporal microbial community dynamics within soil aggregates. Soil Biol. Biochem. 2019, 132, 58-68. [CrossRef]

76. Lixia, Z.; Mingmao, D. Soil microbial characteristics as bioindicators of soil health. Biodivers. Sci. 2007, 15, 162-171. [CrossRef]

77. Susic, M. Replenishing humic acids in agricultural soils. Agronomy 2016, 6, 45. [CrossRef]

78. Fu, W.; Fan, J.; Wang, S.; Wang, H.; Dai, Z.; Zhao, X.; Hao, M. Woody peat addition increases soil organic matter but its mineralization is affected by soil clay in the four degenerated erodible soils. Agric. Ecosyst. Environ. 2021, 318, 107495. [CrossRef]

79. Cui, T.; Li, Z.; Wang, S. Effects of in-situ straw decomposition on composition of humus and structure of humic acid at different soil depths. J. Soils Sedim. 2017, 17, 2391-2399. [CrossRef]

80. Liang, B.; Yang, X.; He, X.; Zhou, J. Effects of 17-year fertilization on soil microbial biomass $\mathrm{C}$ and $\mathrm{N}$ and soluble organic $\mathrm{C}$ and $\mathrm{N}$ in loessial soil during maize growth. Biol. Fertil. Soils 2011, 47, 121-128. [CrossRef]

81. Shi, Y.; Lalande, R.; Ziadi, N.; Sheng, M.; Hu, Z. An assessment of the soil microbial status after 17 years of tillage and mineral $\mathrm{P}$ fertilization management. Appl. Soil Ecol. 2012, 62, 14-23. [CrossRef] 